\title{
Molecular mechanisms of Sar/Arf GTPases in vesicular trafficking in yeast and plants
}

\author{
Tomohiro Yorimitsu ${ }^{1}$, Ken Sato ${ }^{1}$ and Masaki Takeuchi ${ }^{2 *}$ \\ ' Department of Life Sciences, Graduate School of Arts and Sciences, University of Tokyo, Tokyo, Japan \\ 2 Department of Chemistry, Graduate School of Science, University of Tokyo, Tokyo, Japan
}

\section{Edited by:}

Shingo Nagawa, Chinese Academy

of Sciences, China

\section{Reviewed by:}

David Gordon Robinson, University of Heidelberg, Germany

Ken Matsuoka, Kyush University, Japan

*Correspondence:

Masaki Takeuchi, Department of Chemistry, Graduate School of

Science, University of Tokyo, Tokyo 113-0033, Japan

e-mail: take@chem.s.u-tokyo.ac.jp
Small GTPase proteins play essential roles in the regulation of vesicular trafficking systems in eukaryotic cells. Two types of small GTPases, secretion-associated Ras-related protein (Sar) and ADP-ribosylation factor (Arf), act in the biogenesis of transport vesicles. Sar/Arf GTPases function as molecular switches by cycling between active, GTP-bound and inactive, GDP-bound forms, catalyzed by guanine nucleotide exchange factors and GTPase-activating proteins, respectively. Activated Sar/Arf GTPases undergo a conformational change, exposing the $\mathrm{N}$-terminal amphipathic $\alpha$-helix for insertion into membranes. The process triggers the recruitment and assembly of coat proteins to the membranes, followed by coated vesicle formation and scission. In higher plants, Sar/Arf GTPases also play pivotal roles in maintaining the dynamic identity of organelles in the secretory pathway. Sar1 protein strictly controls anterograde transport from the endoplasmic reticulum (ER) through the recruitment of plant COPII coat components onto membranes. COPII vesicle transport is responsible for the organization of highly conserved polygonal ER networks. In contrast, Arf proteins contribute to the regulation of multiple trafficking routes, including transport through the Golgi complex and endocytic transport. These transport systems have diversified in the plant kingdom independently and exhibit several plant-specific features with respect to Golgi organization, endocytic cycling, cell polarity and cytokinesis. The functional diversification of vesicular trafficking systems ensures the multicellular development of higher plants. This review focuses on the current knowledge of Sar/Arf GTPases, highlighting the molecular details of GTPase regulation in vesicle formation in yeast and advances in knowledge of the characteristics of vesicle trafficking in plants.

\section{Keywords: small GTPase, vesicular trafficking, endoplasmic reticulum, Golgi apparatus, endosome}

\section{INTRODUCTION}

Eukaryotes utilize guanine nucleotides to regulate many intracellular cellular processes, including the endomembrane vesicular trafficking system. In general, trafficking is turned on when a "switch" molecule is activated by binding to GTP; in contrast, the system is off when the molecule is in the inactive, GDP-bound form. This on-off action is cycled consecutively via control of the activity of the switch molecule. To maintain homeostasis, cells require the integrity of membrane trafficking resulting from accurate switch activity. Secretion-associated Ras-related (Sar) and ADP-ribosylation factor (Arf) of small GTPase family proteins belong to the Ras superfamily and serve as such switch molecules for the precise operation of vesicular trafficking systems. The Sar/Arf proteins are highly conserved among species from yeast to mammals as well as in plants and are classified based on amino acid sequence homology. Sarl was first identified as a multicopy suppressor of a temperature-sensitive sec 12 mutant in S. cerevisiae (Nakano et al., 1988). Higher eukaryotes have more than two Sar1 orthologs (e.g., two genes in vertebrates), whereas S. cerevisiae has only one Sar1. In contrast, several Arf genes are found in various species (three genes in yeast and six in mammals). The first Arf,
Arf1, was cloned from bovine and yeast and has been identified as the cofactor for activating the ADP-ribosylation of a heteromeric G protein by cholera toxin in vitro (Kahn et al., 1988; Sewell and Kahn, 1988). Arf proteins are categorized into three classes. Although mammals have all classes, Classes I, II and III, yeast and plants lack Class II. Arf1, belonging to Class I, is the best studied, especially with regard to its role in vesicular trafficking.

To date, a large number of genes of the Sar/Arf proteins have been identified in plants (Jurgens and Geldner, 2002; Vernoud et al., 2003), and the complementation of yeast mutants has been a useful tool to isolate and characterize these genes (D'Enfert et al., 1992; Kim et al., 1997; Takeuchi et al., 1998, 2000, 2002; De Craene et al., 2014). Regulators and other interacting proteins of these GTPases have also been identified in plants by the use of yeast mutants and amino acid sequence similarity to yeast and mammalian orthologs (Vernoud et al., 2003). In the genome of the model plant Arabidopsis thaliana, four SAR1 genes exist, which form a small gene family; in contrast, there are 12 $A R F$ genes, comprising a multiple gene family (Robinson et al., 2007). In comparison with Arabidopsis Sarl proteins, Arabidopsis Arf proteins appear to be involved in many different vesicular 
trafficking routes. Their trafficking systems have diversified in the plant kingdom independently of other organisms and are deeply involved in several plant-specific features. Thus, the functional diversification of vesicular trafficking systems is key to understanding the multicellular development of higher plants.

\section{Sar1/Arf1 SMALL GTPases}

Sar1/Arf1 proteins bidirectionally manage vesicular trafficking in the early secretory pathway between the ER and Golgi: the anterograde pathway from the ER to Golgi depends on Sar1, whereas the opposite retrograde pathway from the Golgi to ER depends on Arf1. Distinct sets of vesicles move forward and backward and transfer proteins and lipids via these pathways. The transport vesicles are covered with distinct sets of coat protein (COP) complexes and bud specifically from donor organelle membranes (Brandizzi and Barlowe, 2013). COPII-coated vesicles are derived from the ER membrane and carry substances to the Golgi, and COPI-coated vesicles are derived from Golgi membranes to mediate transport to the ER. To ensure proper vesicle formation, COPI and COPII proteins consisting of completely different components should be properly recruited to each organelle membrane. For this purpose, Sar1/Arf1 proteins are switched on and off as appropriate on the respective organelle membranes by specific regulators that convert their guanine nucleotide-binding state.

Sar1/Arf1 proteins are primarily responsible for the recruitment of COP proteins to membranes and initiation of the formation of COP-mediated vesicles. These proteins share structural similarity despite their different sequence identity (Figure 1A). At the initial step of COP vesicle formation, the two proteins function as switch molecules by similar mechanisms. The Sar1/Arf1 proteins have a characteristic $\alpha$-helix at the $\mathrm{N}$-terminal end that is composed of approximately 20 hydrophobic and hydrophilic amino acid residues, resulting in its amphipathic nature (Antonny et al., 1997; Bielli et al., 2005; Lee et al., 2005). When bound to GDP, Sar1/Arf1 proteins are cytosolic and inactive: the amphipathic $\alpha$-helix is sequestered in a hydrophobic pocket on the surface. The exchange of GDP for GTP induces a conformational change into the active form (Figure 1B); in this conformation, a loop region flanked by $\beta$-sheets between two switch domains (the so-called interswitch region) is displaced from the nucleotidebinding site, which forces exposure of the helix out of the hydrophobic pocket (Goldberg, 1998; Bi et al., 2002). However, the extruded helix requires engagement in a suitable hydrophobic environment because of its amphipathicity. As a consequence of the hydrophobic face of the helix being laterally inserted into the outer leaflet of the lipid bilayer, GTP-loaded active Sar1/Arf1 proteins associate stably with the donor organelle membrane.

The N-terminal helix is also used to deform the membrane (Bielli et al., 2005; Lee et al., 2005; Beck et al., 2008; Krauss et al., 2008; Lundmark et al., 2008). In vitro experiments show that when mixed with purified Sar1/Arf1 protein, liposomes are deformed into a highly curved tubular structure. This tubulation process requires the hydrophobicity of the N-terminal amphipathic helix. In contrast, a Sar1 mutant lacking the Nterminal helix is still able to deform an artificial liposome membrane in vitro (Stachowiak et al., 2012). When chemically

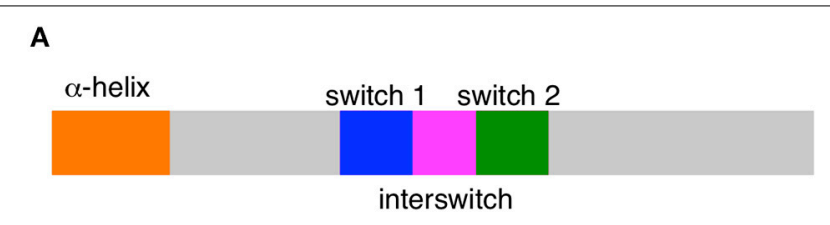

B

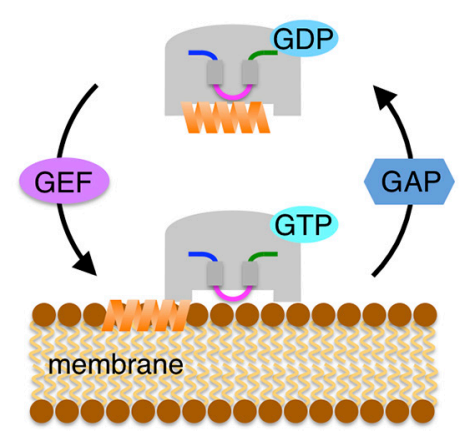

FIGURE 1 | Small GTPase Sar1/Arf1 protein. (A) Schematic diagrams of Sar/Arf. Conserved domains are depicted: the N-terminal amphipathic $\alpha$-helix, two switch regions (switch 1 and switch 2) and the interswitch region. (B) The Sar/Arf protein cycles between membrane-association and dissociation. GDP-bound cytosolic Sar/Arf is inactive and carries the $\mathrm{N}$-terminal amphipathic helix in a hydrophobic pocket. A guanine nucleotide exchange factor (GEF) mediates the exchange of GDP for GTP in Sar/Arf. GTP-loaded Sar/Arf undergoes a conformational change of the two switch and interswitch regions, triggering the extrusion of the helix from the pocket. Subsequently, the shallow insertion of the amphipathic helix into the outer leaflet of the lipid bilayers allows Sar/Arf to associate tightly with the membrane surface. For dissociation, GTPase activating protein (GAP) activates the GTP hydrolysis activity of Sar/Arf. Conserved domains are shown in the same color in (A) and (B).

bound to the lipid, the Sar1 mutant protein accumulates in the subdomain; in this case, the crowding of Sar 1 on the membrane surface drives the tubulation. Tubular structures could be involved physiologically with non-vesicular carriers for ERGolgi transport, as suggested by several observations in various organisms, including yeast (Fatal et al., 2004; Mironov, 2014). Further study is necessary for a better understanding of a role of Sar1/Arf1-formed tubular structures in biological processes in vivo.

Arf family proteins such as Arfl possess a modification of a myristoyl moiety on the N-terminal helix, which is required for potential biological activity as well as membrane association (Kahn et al., 1988, 1995; Franco et al., 1996) (Figure 2). Sar1 does not undergo such modifications. Myristoylation occurs cotranslationally on the N-terminal second glycine residue of Arf exposed after cleavage of the first methionine residue, which contributes to increased hydrophobicity of the N-terminal amphipathic helix. Without the exposed helix, GDP-loaded inactive Arf1 associates unstably with membranes solely through the myristoyl group. Hence, the hydrophobic nature due to both is required for stable membrane association of GTP-bound Arfl.

\section{GUANINE NUCLEOTIDE EXCHANGE FACTORS}

In the presence of $\mathrm{Mg}^{2+}$ and liposomes, the spontaneous exchange of GDP to GTP occurs efficiently in Sar1/Arf1 proteins 


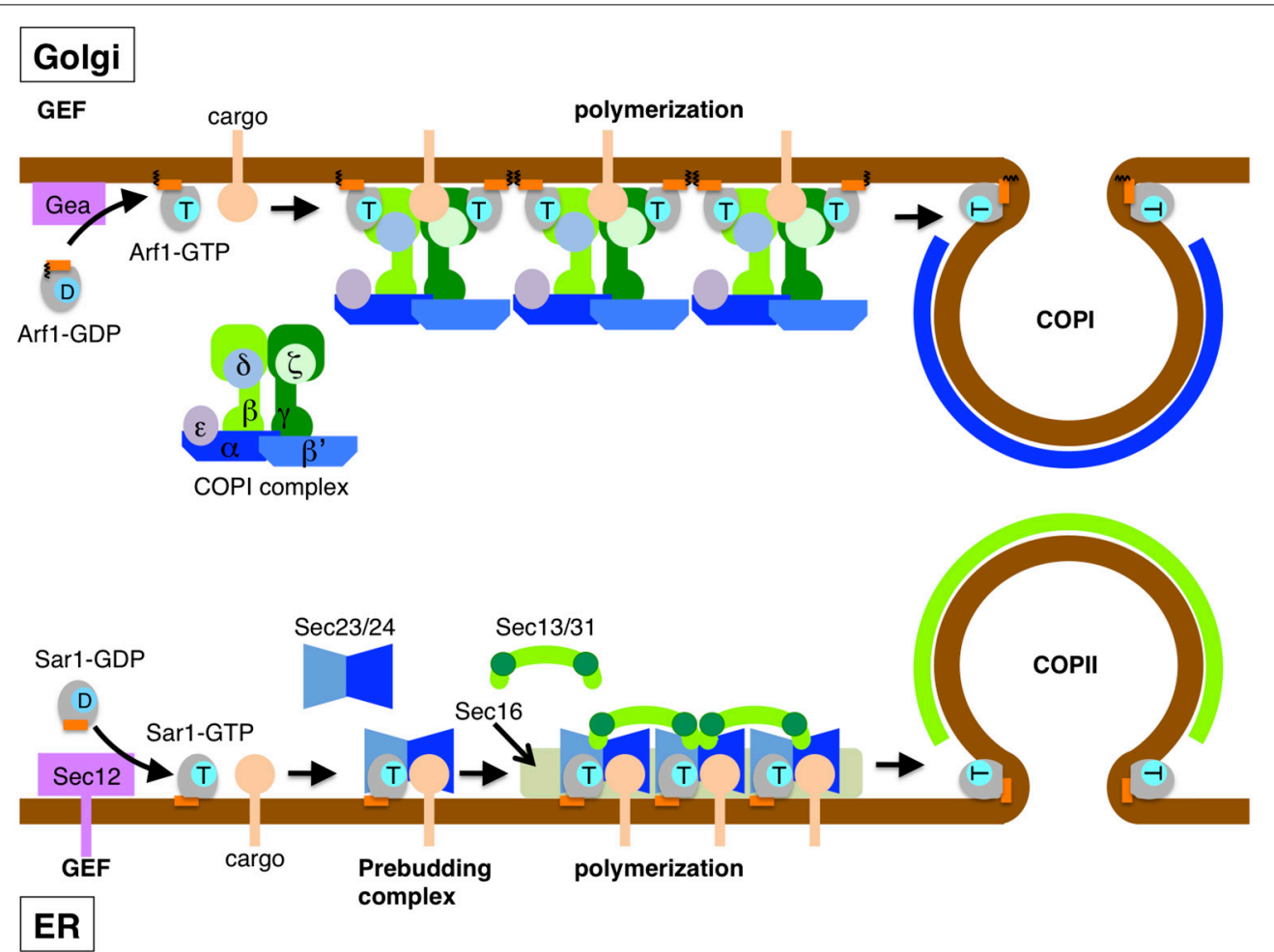

FIGURE 2 | Assembly of COPII and COPI coats drives vesicle formation. Vesicle formation starts upon the recruitment of Sar1 and Arf1 to the ER (lower) and Golgi membranes (upper), respectively. In COPII vesicle formation, the ER integral membrane protein Sec12 exchanges GDP for GTP bound to Sar1 through its GEF activity. Membrane-associated GTP-bound Sar1 recruits the inner coat Sec23/24 complex and then assembles along with cargo protein into the pre-budding complex. Outer coat Sec13/31 complexes are recruited to the pre-budding complexes and self-assembled by crosslinking. The polymerization of Sec13/31 by self-assembly drives membrane curvature to form a spherically shaped vesicle. COPI vesicle formation is also initiated by GTP-GDP exchange on Arf1 through the action of the GEF Gea protein (Gea1 or Gea2), which is peripherally located on the Golgi membrane. GTP-bound Arf1 stably binds to the membrane by a myristoylated amphipathic helix, as does Sar1. The heptamer complex of the COPI coat is recruited en bloc and associates with cargo as well as two Arf1 molecules though the inner layer coat complex $(\beta / \gamma / \delta / \zeta$-COP). As in COPII, vesicles are formed upon polymerization of the outer coat $\left(\alpha / \beta^{\prime} / \varepsilon-C O P\right)$. The amphipathic helix of Sar1 and Arf1 has some role in the scission of budded vesicles. in vitro (Barlowe et al., 1993; Franco et al., 1996). However, GDP-GTP exchange in vivo relies on a catalytically assisting protein called guanine nucleotide exchange factor (GEF). Because free GTP is much more abundant than free GDP in cells, the release of GDP from a nucleotide-binding site is sufficient to complete GDP-GTP exchange. A specific GEF protein catalyzes the conversion from the inactive state to active state of Sar1 and Arf1 on the appropriate organelle membrane (Figure 1B). Sec12 is a type II transmembrane protein localizing at the ER and exclusively acts as the GEF for Sar1. Sec12 was originally identified from yeast mutants defective in ER-Golgi transport (Novick et al., 1980). Its catalytic domain facing the cytosol is composed of a seven-bladed $\beta$-barrel structure, from which a loop with $\mathrm{K}^{+}$ bound (termed the K loop) extends (McMahon et al., 2012). Catalytically essential residues have been identified around the $\mathrm{K}$ loop. Accordingly, it is proposed that Sec12 contacts GDP-loaded Sar1 through the loop, mediating the conversion of the GDPbound to GTP-bound form of Sar1. The transmembrane domain of Sec12 has an important role in its appropriate ER localization, ensuring strict Sar1 recruitment to the ER membrane. In yeast, when Sec12 escapes from the ER, the Golgi protein Rer1 retrieves
Sec12 back to the ER by recognizing its transmembrane domain (Sato et al., 1996).

In contrast, Arf GEF proteins are more diverse (Anders and Jurgens, 2008). Unlike Sec12, Arf GEF proteins localize peripherally to membranes and possess a conserved Sec7 domain to exert their GEF activity. In yeast, Arf1 has four GEF proteins, and two of them, Gea1 and Gea2, play a redundant role in Arf1 activation to regulate COPI vesicle formation (Peyroche et al., 1996, 2001). The Gea protein is soluble but is partially recruited to cis-Golgi membranes because of cycling between the cytosol and membrane. The Golgi transmembrane protein Gmh1 was identified as an interactor of Gea and a potential candidate for the membrane recruitment of the Gea protein (Chantalat et al., 2003). However, as Gmh1 depletion did not have a strong effect on the membrane association of the Gea protein, it remains unknown how Gea associates with membranes. Although in vitro reconstitution experiments have clearly demonstrated that Sec12 and Gea constitutively facilitate GDP-GTP exchange in Sar1 and Arf1, respectively (Peyroche et al., 1996; Futai et al., 2004), it is unclear whether and how such catalytic activity is controlled in vivo. 


\section{GTPase ACTIVATING PROTEINS AND THEIR REGULATION}

GTP-locked mutant forms of Sar1 and Arf1 display dominantnegative effects, indicating that accomplishment of the GTPase cycle is physiologically essential (Kahn et al., 1995; Saito et al., 1998). The Sar1/Arf1 protein displays little or no intrinsic GTP hydrolysis activity, though each protein has specific GTPaseactivating protein (GAP) partners, which simply evoke a reaction opposite to that of GEF (Figure 1B). When a GAP activates the GTP hydrolysis activity, the Sar1/Arf1 protein is inactivated and dissociates from the membrane. However, their physiological functions extend beyond that.

After association with the ER membrane, GTP-bound active Sar1 recruits the COPII coat subunit of the Sec23/24 heterodimer complex from the cytosol (Matsuoka et al., 1998) (Figure 2). Of the complex, Sec23 forms a direct interaction with Sar1 and also acts as its GAP (Yoshihisa et al., 1993). The crystal structure reveals the molecular mechanism by which Sec23 stimulates Sar1 GTPase activity, whereby Sec23 inserts a key arginine residue into the active site of Sar1 (Bi et al., 2002). However, the Sec23-stimulated GTPase activation of Sar1 is relatively inefficient for triggering full coat disassembly (Antonny et al., 2001). Sec24 captures the transmembrane cargo protein and the adaptor/receptor protein for the soluble cargo existing in the ER lumen by binding to the cytosolic tail (Miller et al., 2003; Mossessova et al., 2003). The Sar1/Sec23/24/cargo complex, termed the prebudding complex, is relatively stable enough to prevent coat disassembly. Conversely, when the Sar1/Sec23/24 complex fails to capture cargo by Sec 24 dissociating from the membrane, each dissociated protein is recycled again to form the pre-budding complex properly (Koizumi et al., 2005). In yeast, an ER integral membrane protein, Sed4, potentially plays some role in this process (Espenshade et al., 1995; Kodera et al., 2011). Sed4 interacts directly with Sar1 but has no GEF activity for Sar1, despite high similarity of the N-terminal, cytosolic domain with Sec12. Instead, Sed4 exhibits stimulation of Sec23-mediated as well as intrinsic Sar1 GTPase activity and the acceleration of coat disassembly only in the absence of cargo proteins. Thus, Sed4 is proposed to have a role in efficient recycling of the coat and Sar1 by disassembly of the Sar1-Sec23/24 complex that is free of cargo. Further study is required to clarify the mechanisms of Sar1 GTPase activation by Sed4.

At the next step, the prebudding complex recruits Sec13/31 heterotetramer complexes, which form the outer coat, to crosslink the adjacent prebudding complexes via polymerization (Matsuoka et al., 1998; Tabata et al., 2009) (Figure 2). A cryoelectron microscopy study has revealed that purified Sec13/31 complexes self-assemble to form a spherical lattice-like structure in solution, the size and shape of which closely fit with those of COPII vesicles (Stagg et al., 2006). Accordingly, lateral Sec13/31 polymerization could incorporate the cargo into a nascent vesicle and simultaneously drive membrane curvature to form the precise vesicular shape. In addition to the scaffolding role, Sec31 acts as the Sec23 GAP stimulator. The crystal structure of the active fragment of Sec31 with the Sar1/Sec23 complex reveals insight into the mechanisms of GAP stimulation (Bi et al., 2007). Sec31 has a C-terminal proline-rich domain as the GAP stimulator. Within the complex, this domain binds across the extended surface of Sec23 and Sar1 and accesses the active site to optimize the orientation of the catalytically important histidine residue of Sar1. Taken together, there are two-step processes for Sec23 GAP activity and Sec31 GAP stimulation for the full activation of Sar1 GTP hydrolysis.

This two-step activation system has been successfully reproduced in minimal reconstitution experiments with liposomes (Antonny et al., 2001). In these experiments, however, full activation of the Sar1 GTPase causes the membrane-associated coat to be rapidly disassembled. To overcome this paradoxical situation, there are at least two potential solutions, as mentioned above: the constant activation of Sec12 GEF and a contribution by cargo molecules to stabilizing the prebudding complex (Futai et al., 2004; Koizumi et al., 2005). In addition, a peripheral ERmembrane protein, Sec16, acts as a GAP inhibitor to contribute to stable coat assembly. Sec16 is an essential protein for COPII vesicle formation in vivo and interacts with all of the COPII coat proteins through its multiple domains at vesicle-formation sites on the ER and ER exit sites (Espenshade et al., 1995; Shaywitz et al., 1997; Supek et al., 2002; Connerly et al., 2005). Recent studies have reported that Sec16 not only functions as a recruiter of the coat but also modulates the interaction of Sec31 with the Sar1/Sec23/24 complex (Kung et al., 2012; Yorimitsu and Sato, 2012). Although the detailed mechanisms still remain elucidated, Sec16 might interfere with the catalytic interaction between the active domain of Sec31 and the Sar1/Sec23 complex.

GTP-bound Arf1 primes COPI coat assembly to the Golgi membrane. The COPI coat is composed of seven proteins, $\alpha$ (Cop1), $\beta$ - (Sec26), $\beta^{\prime}-(\operatorname{Sec} 27), \gamma-(\operatorname{Sec} 21), \delta$ - (Ret2), $\varepsilon-$ and $\zeta$-COP (Ret3), with the corresponding yeast proteins in parentheses. Although biochemically separable into two subcomplexes of $\alpha / \beta^{\prime} / \varepsilon$-COP and $\beta / \gamma / \delta / \zeta$-COP, the COPI coat complex is recruited en bloc to the Golgi membrane through the direct interaction with membrane-bound Arf1 (Hara-Kuge et al., 1994) (Figure 2). $\alpha / \beta^{\prime} / \varepsilon$-COP forms the cage-like structure of the outer layer coat that resembles Sec13/31 and clathrin structures (Lee and Goldberg, 2010). $\beta / \gamma / \delta / \zeta$-COP serves as the inner coat to capture cargo proteins, with $\gamma / \zeta$-COP being structurally similar to the $\alpha / \sigma$ adaptins of the AP2 clathrin adaptor (Yu et al., 2012). Two molecules of Arf1 interact with the inner COPI coat through the $\beta$-COP and $\gamma$-COP subunits. Although likely analogous to the COPII coat, COPI itself has no GAP function. Alternatively, the GAP protein ArfGAP1 separately serves as the Arf1 GTPase activator in COPI vesicle formation. Similar to the COPII systems, the $\beta$-COP and $\gamma$-COP coat subunits possess the ability to promote the GAP activity of Arf1 in solution (Yu et al., 2012), although the mechanisms remain to be elucidated. In reconstitution systems with synthetic liposomes, GAP is not always essential for vesicle formation (Spang et al., 1998). In other cases, GAP promotes COPI vesicle formation, with cargo proteins having a key role. Similar to the step of the pre-budding complex formation of COPII, in a situation in which there is no cargo, Arf1 GTP hydrolysis drives the dissociation of the coat from the membrane and then reuses it until cargo is captured.

Successful Arf1/COPI/cargo complexes move to the vesicle-forming step by coat polymerization, and finally cargo-incorporated COPI vesicles bud and form (Spang et al., 
2010; Shiba and Randazzo, 2012). Gcs1 and Glo3 in yeast serve as the Arf1 GAP in COPI vesicle formation. These two proteins are distinct in structure and partially overlap in function (Poon et al., 1999). Gcs1 belongs to the ArfGAP1 family, whereas Glo3 belongs to the ArfGAP2/3 family; both have conserved GAP catalytic domains at the N-terminus. Only Gcs1 has a specific lipid-binding motif at the C-terminus, which mediates the preferential association with highly curved membranes, which is suggested to have some role in regulating Gcs1 GAP activity (Bigay et al., 2005). In contrast, Glo3 does not have an obvious lipid-binding motif. Yeast mutants lacking either the GCS1 or GLO3 gene grow well, whereas the double-deletion mutant is lethal (Poon et al., 1999). Gcs1 and Glo3 suppress the lethality of an Arf1-malfunctional mutant when overexpressed and may also have a potential function in the formation of the Arf1/COPI coat/cargo complex, which again supports the idea that Arf1 GAP plays a positive role in vesicle formation (Zhang et al., 1998). The precise functions of GAP remain controversial, and further studies are required for a comprehensive model.

As mentioned above, the functional role of GTP hydrolysis is in the efficient formation of selective cargo-incorporated vesicles by cycling the disassembly and assembly of the coat to allow its successful capture of cargo. A second role is suggested in the scission of the budded vesicle from the membrane. It was shown that the release of the COPII vesicle is inhibited in the presence of a Sar1 mutant lacking the N-terminal amphipathic helix or GTP hydrolysis activity. However, there is conflicting evidence showing that vesicles are successfully formed in the presence of the non-hydrolyzable GTP analog GMP-PNP. Another role is coat dissociation from the completed vesicle prior to arrival at the acceptor organelle. Fusion with the organelle membrane requires at least a partially uncoated, naked part on the vesicle membrane. Uncoating due to the inactivation of Sar1/Arf1 proteins can employ activated GAP. However, it is unknown when and how GAP is activated to hydrolyze GTP on Sar1/Arf1 proteins. It was shown that only a small amount of Sarl proteins are detected from isolated formed vesicles (Barlowe et al., 1994). It is possible that during budding and/or just before completion, at least partial portion of the Sar1/Arf1 proteins were released from the membrane surface of coated vesicles by the action of GAP. This fits with the observation that the TRAPPI complex and Ypt1, which serve in the tethering event, can bind to COPII vesicles through the interaction with Sec23 after Sar1 is depleted (Cai et al., 2007; Lord et al., 2011). Subsequently, at the Golgi surface, the Hrr25 protein kinase, in association with the Golgi, phosphorylates Sec23/24 to release the coat and eventually promote vesicle fusion. In this model, however, it remains unknown how coat proteins are retained on the forming and formed vesicles without the action of Sar1.

\section{PLANT VESICULAR TRAFFICKING}

In plant cells, the secretory pathway exports a variety of proteins to the cell surface and is essential for the expansion and elongation of the cells. The major molecular components in secretory systems are well conserved among eukaryotes. However, the morphological properties of the secretory organelles show great divergence between plants and mammals. The characteristic features of plant secretion, such as the formation of cell plates during cytokinesis, a polydisperse mobile Golgi apparatus and the lack of an intermediate compartment between the ER and the Golgi apparatus, expand many plant-specific molecules in the maintenance and regulation of vesicular trafficking through the secretory pathway. The development and morphogenesis of higher plants require the strict regulation of vesicular trafficking. To elucidate vesicular trafficking in plants, fluorescent proteins have been extensively utilized for the visualization of proteins localizing at various membrane-bound compartments. The advent of live cell imaging utilizing fluorescently tagged proteins has provided unprecedented insight into the movement of proteins and their interactions in plant studies.

\section{PLANT Sar1 PROTEINS AND THEIR INTERACTING PROTEINS}

To investigate the roles of Sar1 proteins in plant cells, a system that utilizes their dominant-negative mutants was established. From the knowledge accumulated in yeast and mammalian studies, mutants that are virtually fixed at the GTP- or GDP-bound state, which act dominantly over the wild-type protein, were constructed. By the transient expression of such dominant mutants of Arabidopsis Sar1 protein (AtSar1) and green fluorescent protein (GFP)-tagged marker proteins, it was demonstrated that AtSarl is required for transport from the ER to the Golgi apparatus (Takeuchi et al., 2000). This transient expression system in plant cells also provides a tool to manipulate membrane traffic by GTPase mutants, even when their effects are toxic for cell growth. Similar molecular approaches have also been successfully applied for the study of other GTPases and secretory genes (Batoko et al., 2000; Phillipson et al., 2001). Regardless, it took time before the conditional expression of dominant-negative plant Sar1 became possible in stable transgenic plants (Osterrieder et al., 2010). The inducible expression of a GTP-locked mutant of tobacco Sar1 enabled the investigation of protein dynamics after the blockade of ER-to-Golgi transport at the electron microscopic level (Osterrieder et al., 2010).

The Arabidopsis genome encodes several COPII components, four Sar1, seven Sec23, three Sec24, two Sec13, and two Sec31 (Robinson et al., 2007) (Table 1). Regarding Sar1, Sec24 and Sec13 isoforms, functional complementation was reported through yeast expression studies (D'Enfert et al., 1992; Takeuchi et al., 1998; De Craene et al., 2014). A functional heterogeneity among plant Sar1 isoforms was reported for the function of plant Sar1 (Hanton et al., 2008). Yellow fluorescent protein (YFP) fusions of two Arabidopsis Sar1 isoforms were differently localized at the ERES and showed different levels of partition with the membrane fraction. In addition, functional analyses using a secretion marker protein indicated that the overexpression of GTP-locked mutants of the two Sar1 isoforms caused different levels of ER export inhibition (Hanton et al., 2008). In rice (Oryza sativa), four Sarl isoforms (OsSarla, OsSar1b, OsSar1c, and OsSar1d) were cloned and characterized (Tian et al., 2013). Gene suppression experiments by RNA interference revealed that single knock down of one of the OsSar1 isoforms showed no obvious phenotype but simultaneous knock down of OsSar $1 \mathrm{a} / \mathrm{b} / \mathrm{c}$ resulted in floury and shrunken seeds and caused the generation of numerous novel protein bodies with highly 
Table 1 | Arabidopsis Sar1 proteins and their interacting proteins.

\begin{tabular}{|c|c|c|c|}
\hline Protein & Other name & AGI numbers & $\begin{array}{l}\text { Function or putative } \\
\text { function }\end{array}$ \\
\hline AtSARA1a & AtSar1 & At1g09180 & Small GTPase \\
\hline AtSARA1b & & At1g56330 & Small GTPase \\
\hline AtSARA1c & AtSar2 & At4g02080 & Small GTPase \\
\hline AtSARA1d & & At3g62560 & Small GTPase \\
\hline Sec12 & & At2g01470 & $\begin{array}{l}\text { Guanine nucleotide } \\
\text { exchange factor (GEF) for } \\
\text { Sar1 }\end{array}$ \\
\hline Sec23 & & $\begin{array}{l}\text { At3g23660 } \\
\text { At1g05520 } \\
\text { At5g43670 } \\
\text { At4g14160 } \\
\text { At2g21630 } \\
\text { At4g01810 } \\
\text { At2g27460 }\end{array}$ & $\begin{array}{l}\text { GTPase-activating protein } \\
\text { (GAP) for Sar1 }\end{array}$ \\
\hline Sec24 & & $\begin{array}{l}\text { At3g07100 } \\
\text { At3g44340 } \\
\text { At4g32640 }\end{array}$ & $\begin{array}{l}\text { Coat protein for } \\
\text { COPIl vesicle }\end{array}$ \\
\hline Sec13 & & $\begin{array}{l}\text { At3g01340 } \\
\text { At2g30050 }\end{array}$ & $\begin{array}{l}\text { Coat protein for } \\
\text { COPII vesicle }\end{array}$ \\
\hline Sec31 & & $\begin{array}{l}\text { At1g18830 } \\
\text { At3g63460 }\end{array}$ & $\begin{array}{l}\text { Coat protein for } \\
\text { COPII vesicle }\end{array}$ \\
\hline Sec16 & & $\begin{array}{l}\text { At5g47480 } \\
\text { At5g47490 }\end{array}$ & $\begin{array}{l}\text { Scaffold protein at } \\
\text { ER exit sites }\end{array}$ \\
\hline
\end{tabular}

electron-dense matrixes containing both glutelin and $\alpha$-globulin in the endosperm of transgenic plants, suggesting the presence of a functional redundancy among rice Sar1 isoforms (Tian et al., 2013).

Arabidopsis plants possess three types of Sec24 isoforms (AtSec24A, AtSec24B and AtSec24C) (Robinson et al., 2007). An Arabidopsis missense recessive mutation in sec $24 A$ showed an aberrant phenotype, with partially accumulated Golgi membrane markers and a soluble secretory marker in globular structures composed of large amounts of convoluted ER membranes (Faso et al., 2009; Nakano et al., 2009). Only AtSec24A, but not other AtSec24 isoforms, could complement these mutant phenotypes. The complete loss of $\sec 24 A$ function led to a lethal phenotype, suggesting that AtSEC $24 A$ is an essential gene. In contrast, AtSec24B knockout plants merely showed mild male sterility, with a reduction of pollen germination, and AtSec $24 \mathrm{C}$ knockdown plants showed an aberration in female gametogenesis (Tanaka et al., 2013). These results suggest that the functional diversification of plant COPII components occurred in the regulation of the plant early secretory pathway to maintain the dynamic identity of secretory organelles.

In recent studies of plant vesicular trafficking, the spatial relationship between the ERES and Golgi apparatus has been a matter of controversy because exit from the ER has been difficult to visualize, and interpretations of the same observations have not necessarily reached a consensus. To explain these contradictions, two typical models have been proposed by two groups about the organelle relationship (Dasilva et al., 2004; Yang et al., 2005). One model predicts that protein export from the ER occurs via the sequential recruitment of inner and outer COPII components to form transport intermediates at the mobile, Golgi-associated ERES. The other model predicts that the Golgi apparatus is not continually linked to a single ERES; instead, Golgi stacks associate intermittently and sometimes concurrently with several ERES as they are moving around in the cells. It was proposed that general differences in Golgi motility between plant leaves and suspension cells could be the reason for these discrepancies (Marti et al., 2010). More recently, to investigate plant ER import site (ERIS) where retrograde COPI vesicle fuse, fluorescence imaging experiments were performed and revealed that a Golgi-associated mobile domain of the ER, which is labeled by SYP72-YFP, play pivotal roles in COPI vesicle fusion and COPII vesicle budding as a common platform (Langhans et al., 2012; Lerich et al., 2012). Furthermore, COPI vesicle fusion with the ER is restricted to periods when Golgi stacks are stationary, but that when moving both COPII and COPI vesicles are tethered and collected in the ERGolgi interface. These findings established a new model where the Golgi stack and an associated domain of the ER thereby constitute a mobile secretory and recycling unit (Langhans et al., 2012; Lerich et al., 2012). This is a characteristic feature in plant cells. Most recently, another imaging study using yeast system reported that direct contact of cis-Golgi with the ERES executes cargo capture and delivery from the ER (Kurokawa et al., 2014).The structural relationship between the mobile unit system in plants and the direct contact system in yeast remains to be clarified in future studies.

In higher plants, a functional differentiation has emerged in the mechanism of protein export from the ER (Gonzalez et al., 2005). In Arabidopsis, the PHOSPHATE TRANSPORTER1 (PHT1) gene family encodes phosphate $(\mathrm{Pi})$ transporters that play a fundamental role in $\mathrm{Pi}$ acquisition and remobilization in plants. Mutation of PHOSPHATE TRANSPORTER TRAFFIC FACILITATOR1 (PHF1) caused impairment of Pi transport, resulting in the constitutive expression of many Pi starvationinduced genes and reduced $\mathrm{Pi}$ accumulation (Gonzalez et al., 2005). PHF1 encodes a plant-specific protein family conserved in Arabidopsis, rice and tomato. Their protein structures are related to the SEC12 proteins but lack most of the conserved domains of SEC12 proteins essential as guanine nucleotide exchange factors. Arabidopsis PHF1 was found to be localized to the ER, and its mutation caused the ER retention and reduced accumulation of the plasma membrane transporter PHT1;1. In contrast, both the plasma membrane localization and secretion of other proteins were not affected in this mutant. These results indicate that plants have evolved a novel mechanism that enables the cargo-specific protein export of Pi transporters from the ER.

\section{PLANT Arf PROTEINS AND THEIR INTERACTING PROTEINS}

The fact that 12 Arf proteins exist in Arabidopsis indicates that functional specialization has substantially occurred in the plant Arf protein family (Table 2 ). In addition to this, when taken into consideration that the single Arf1 protein executes multiple functions, including roles in Golgi-to-ER retrograde traffic and post-Golgi traffic in yeast (Yahara et al., 2001), it is quite difficult to elucidate all the functions of plant Arf proteins. 
Table 2 | Arabidopsis Arf proteins and their interacting proteins.

\begin{tabular}{|c|c|c|c|}
\hline Protein & Other name & AGI numbers & $\begin{array}{l}\text { Function or } \\
\text { putative } \\
\text { function }\end{array}$ \\
\hline AtARFA1a & ARF1A/AtArf1 & At1g23490 & Small GTPase \\
\hline AtARFA1b & ARF1A & At5g14670 & Small GTPase \\
\hline AtARFA1c & ARF1A/BEX1 & At2g47170 & Small GTPase \\
\hline AtARFA1d & ARF1A & At1g70490 & Small GTPase \\
\hline AtARFA1e & ARF1A & At3g62290 & Small GTPase \\
\hline AtARFA1f & ARF1A & At1g10630 & Small GTPase \\
\hline AtARFB1a & ARF1B/ARFB & At2g15310 & Small GTPase \\
\hline AtARFB1b & ARF1B & At5g17060 & Small GTPase \\
\hline AtARFB1c & ARF1B & At3g03120 & Small GTPase \\
\hline AtARFC1 & ARF1C & At3g22950 & Small GTPase \\
\hline AtARFD1a & ARF1D & At1g02440 & Small GTPase \\
\hline AtARFD1b & ARF1D & At1g02430 & Small GTPase \\
\hline Coatomer $\alpha$ & & $\begin{array}{l}\text { At1g62020 } \\
\text { At2g21390 }\end{array}$ & $\begin{array}{l}\text { Coat protein for } \\
\text { COPI vesicle }\end{array}$ \\
\hline Coatomer $\beta$ & & $\begin{array}{l}\text { At4g31480 } \\
\text { At4g31490 }\end{array}$ & $\begin{array}{l}\text { Coat protein for } \\
\text { COPI vesicle }\end{array}$ \\
\hline Coatomer $\beta^{\prime}$ & & $\begin{array}{l}\text { At1g52360 } \\
\text { At3g15980 } \\
\text { At1g79990 }\end{array}$ & $\begin{array}{l}\text { Coat protein for } \\
\text { COPI vesicle }\end{array}$ \\
\hline Coatomer $\gamma$ & & At4g34450 & $\begin{array}{l}\text { Coat protein for } \\
\text { COPI vesicle }\end{array}$ \\
\hline Coatomer $\delta$ & & At5g05010 & $\begin{array}{l}\text { Coat protein for } \\
\text { COPI vesicle }\end{array}$ \\
\hline Coatomer $\varepsilon$ & & $\begin{array}{l}\text { At2g34840 } \\
\text { At1g30630 }\end{array}$ & $\begin{array}{l}\text { Coat protein for } \\
\text { COPI vesicle }\end{array}$ \\
\hline Coatomer $\zeta$ & & $\begin{array}{l}\text { At1g60970 } \\
\text { At3g09800 } \\
\text { At1g08520 }\end{array}$ & $\begin{array}{l}\text { Coat protein for } \\
\text { COPI vesicle }\end{array}$ \\
\hline
\end{tabular}

Therefore, limited information has accumulated for plant Arf proteins.

Thus far, the ARF1A subclass is the best-characterized group of the Arabidopsis Arf protein family (Robinson et al., 2007). One of the Arabidopsis Arf1A proteins can complement the lethality of the yeast arf1 arf2 deletion mutant, and its GFP-fusion is localized to the Golgi apparatus in plant cells, as is its animal counterpart (Takeuchi et al., 2002). In vitro COPI-vesicle-generation experiments have demonstrated that Arf1A as well as $\gamma$-COP could be recruited from the cytosol onto mixed ER/Golgi membranes in cauliflower. The presence of plant COPI vesicles was confirmed by in vitro vesicle budding assays coupled with immunogold negative staining (Pimpl et al., 2000). Molecular approaches utilizing the transient expression of GDP- or GTP-locked Arabidopsis Arf1A mutants caused an abrogation of ER-to-Golgi transport and a redistribution of GFP- or YFP-tagged Golgi membrane marker proteins into the ER in plant cells (Lee et al., 2002; Takeuchi et al., 2002; Stefano et al., 2006). These results suggests that plant Arf1A proteins execute highly conserved functions in the formation of COPI vesicles at the Golgi apparatus by recruiting COPI coat complexes to the membranes (Letourneur et al., 1994; Pimpl et al., 2000; Robinson et al., 2007).
In addition to the functional Golgi localization of Arf1A proteins, there is strong evidence that Arf1A localizes to the transGolgi network (TGN) and FM4-64 positive compartments (endosomes). A protoplast-based transient expression study showed that Arf1A proteins are required for the post-Golgi sorting of soluble vacuolar proteins, implying that ArflA is involved in clathrin-coated vesicle formation at the TGN (Pimpl et al., 2003). Visualization of the TGN localization of Arf1A was provided by immunofluorescence studies using transgenic Arabidopsis lines expressing SYP61-CFP and VHA-a1-GFP as TGN markers (Paciorek et al., 2005; Tanaka et al., 2009). Other expression studies using Arf1A-GFP and immunogold electron microscopy demonstrated that Arf1A colocalizes in FM4-64 positive compartments that are distinct from the Golgi apparatus $(\mathrm{Xu}$ and Scheres, 2005; Stierhof and El Kasmi, 2010). In contrast, a recent study of plant-powdery mildew interactions reported that barley (Hordeum vulgare) ARFAlb/1c is localized to multivesicular bodies (MVBs) and required for callose deposition in papillae, leading to penetration resistance against pathogenic fungi (Bohlenius et al., 2010). However, because supporting evidence for this MVB localization is insufficient, it remains unclear whether Arf1A is localized to MVB compartments (Robinson et al., 2011). Therefore, these results indicate that the single Arf1A protein exerts multiple functions in Golgi-to-ER retrograde traffic, post-Golgi traffic and endocytic traffic in plant endomembrane trafficking.

Although Arf1A proteins have been studied primarily at the single-cell level, the developmental functions of the ARF1A subclass of the Arabidopsis Arf family are still unknown at the whole-plant or tissue level. This is because six virtually identical ARF1A genes were found to be ubiquitously expressed and single loss-of-function mutants in these genes revealed no obvious developmental phenotypes. To address the mechanism determining the apical-basal polarity of epidermal cells during plant developmental processes, dominant-negative Arf1A mutants were conditionally expressed by a heat-shock-inducible system in transgenic Arabidopsis. The expression of GDP- or GTP-locked Arf1A mutants caused the abolition of root hair outgrowth at the early stages of root epidermal cell differentiation (Xu and Scheres, 2005). However, unlike in GDP-locked Arf1Amutant-expressing lines, proper root hair formation recovered abruptly in GTP-locked Arf1A-mutant-expressing lines within 2 days, indicating that the effects of the GTP-locked Arf1A mutant on root hair formation were reversible. This difference in the effects caused by the GTP- and GDP-locked mutants of Arf1A on epidermal cell polarity might suggest that they act on different target molecules, with distinct properties in protein level or stability. The heat-shock-inducible expression study also revealed that the plasma membrane localization of a GFPtagged auxin transporter, PIN2-GFP, was slowly affected upon Arf1A manipulation when compared with that of Golgi and endocytic markers. These studies enabled the dissection of the Arf1A functions involved in local and specific aspects of cell polarity (Xu and Scheres, 2005).

Plant Arf proteins are key molecules in the regulation of vesicular trafficking in the multicellular development of plants and are postulated to control both household functions and plant-specific 
functions through interactions with their interacting proteins. Nonetheless, most of the molecular mechanisms of plant-specific functions are still being elucidated. Unlike Arf1A proteins, which are targeted to the Golgi and post-Golgi structures, one of the ARF1B subclass proteins, ARFB, is localized to the plasma membrane (PM) (Matheson et al., 2008). This PM localization is a similar feature with mammalian Class III Arf6 proteins, which specifically play crucial roles in endocytic transport with specific regulators, such as EFA6 and SMAP1, in mammalian systems (Macia et al., 2001; Tanabe et al., 2005). However, it is largely unknown whether ARFB is involved in the regulation of plantspecific functions, including endocytic transport, because information about ARFB is insufficient. The functions and localization of the plant Arf proteins belonging to other subclasses are largely unknown.

Recent studies have revealed that the functional differentiation of the regulator proteins for plant Arf proteins could contribute to the plant-specific functions of vesicular traffic (Table 3). The Arabidopsis Arf-GAP protein family consists of 15 members containing the conserved GAP domain, designated ARF-GAP domain (AGD) proteins (Vernoud et al., 2003). Each AGD protein localizes to its specific cellular membrane compartment. For instance, AGD7 localizes to the Golgi apparatus, where its overexpression was found to inhibit the Golgi localization of $\gamma$-COPs and to induce the relocation of Golgi membrane proteins into the ER in both protoplasts and transgenic plants (Min et al., 2007). Its closely related homologs, AGD8 and AGD9 also localize to the Golgi and are required for the maintenance of Golgi morphology (Min et al., 2013). Gene knockdown experiments by RNA interference revealed that low-level expression of AGD8 and AGD9 induced abnormal Golgi morphology, inhibition of protein trafficking, and arrest of plant growth and development. Conversely, high-level expression of AGD8 and AGD9 evoked Arf1A recruitment to the Golgi and suppressed Golgi disruption and vacuolar trafficking defects that were caused by overexpression of AGD7 (Min et al., 2007, 2013). Imaging studies using protoplasts showed that AGD7, AGD8 and AGD9 can recruit a GDP-locked Arf1A mutant (Arf1 T31N) from the cytosol to the Golgi. Thus, the Golgi-localized ARF-GAPs (AGD7, AGD8 and AGD9) fulfill redundant functions in Arf1A-mediated protein trafficking, which is essential for plant development and growth. Another AGD protein, AGD5, is localized to the TGN, where it co-localizes with Arf1A proteins, central GTPases that play essential roles in plant membrane trafficking at the Golgi and post-Golgi structures. The transient expression of a mutant AGD5 protein having impairment in ARF-GAP activity caused longer recruitment of Arf1A on the membranes, indicating that the GTP hydrolysis of Arf1A was impaired due to a defective GAP (Stefano et al., 2010). These results define a role of AGD5 for Arf1A as an ARF-GAP localizing at the TGN.

Several AGD proteins are specifically expressed in particular plant tissues and play essential roles in tissue formation. AGD12/ZAC has a novel domain structure in which the $\mathrm{N}$ terminal ARF-GAP domain containing a zinc finger domain and a C-terminal C2 domain are separated by a region without homology to other known proteins (Jensen et al., 2000). Expression analyses using a Zac promoter/beta-glucuronidase
Table 3 | Regulators for Arabidopsis Arf proteins.

\begin{tabular}{|c|c|c|c|}
\hline Protein & Other name & AGI numbers & $\begin{array}{l}\text { Function or putative } \\
\text { function }\end{array}$ \\
\hline AGD1 & & At5g61980 & $\begin{array}{l}\text { GTPase-activating } \\
\text { protein (GAP) for Arf }\end{array}$ \\
\hline AGD2 & & At1g60680 & $\begin{array}{l}\text { GTPase-activating } \\
\text { protein (GAP) for Arf }\end{array}$ \\
\hline AGD3 & $\begin{array}{l}\text { VAN3/ } \\
\text { SCARFACE/SFC }\end{array}$ & At4g13300 & $\begin{array}{l}\text { GTPase-activating } \\
\text { protein (GAP) for Arf }\end{array}$ \\
\hline AGD4 & & At1g10870 & $\begin{array}{l}\text { GTPase-activating } \\
\text { protein (GAP) for Arf }\end{array}$ \\
\hline AGD5 & NEV/MTV4 & At5g54310 & $\begin{array}{l}\text { GTPase-activating } \\
\text { protein (GAP) for Arf }\end{array}$ \\
\hline AGD6 & & At3g53710 & $\begin{array}{l}\text { GTPase-activating } \\
\text { protein (GAP) for Arf }\end{array}$ \\
\hline AGD7 & & At2g37550 & $\begin{array}{l}\text { GTPase-activating } \\
\text { protein (GAP) for Arf }\end{array}$ \\
\hline AGD8 & & At4g17890 & $\begin{array}{l}\text { GTPase-activating } \\
\text { protein (GAP) for Arf }\end{array}$ \\
\hline AGD9 & & At5g46750 & $\begin{array}{l}\text { GTPase-activating } \\
\text { protein (GAP) for Arf }\end{array}$ \\
\hline AGD10 & RPA & At2g35210 & $\begin{array}{l}\text { GTPase-activating } \\
\text { protein (GAP) for Arf }\end{array}$ \\
\hline AGD11 & $\begin{array}{l}\text { CML3/ } \\
\text { CALMODULIN- } \\
\text { LIKE3 }\end{array}$ & At3g07490 & $\begin{array}{l}\text { GTPase-activating } \\
\text { protein (GAP) for Arf }\end{array}$ \\
\hline AGD12 & ZAC & At4g21160 & $\begin{array}{l}\text { GTPase-activating } \\
\text { protein (GAP) for Arf }\end{array}$ \\
\hline AGD13 & & At4g05330 & $\begin{array}{l}\text { GTPase-activating } \\
\text { protein (GAP) for Arf }\end{array}$ \\
\hline AGD14 & ZIGA4 & At1g08680 & $\begin{array}{l}\text { GTPase-activating } \\
\text { protein (GAP) for Arf }\end{array}$ \\
\hline AGD15 & & At3g17660 & $\begin{array}{l}\text { GTPase-activating } \\
\text { protein (GAP) for Arf }\end{array}$ \\
\hline Sec7-type & & At4g35380 & $\begin{array}{l}\text { Guanine nucleotide } \\
\text { exchange factor (GEF) } \\
\text { for Arf }\end{array}$ \\
\hline \multirow[t]{4}{*}{ ARF-GEF } & & At4g38200 & \\
\hline & & At1g01960 & \\
\hline & & At3g60860 & \\
\hline & & At3g43300 & \\
\hline GNOM-type & & $\begin{array}{l}\text { At1g13980 } \\
\text { (GNOM) }\end{array}$ & Guanine nucleotide \\
\hline \multirow[t]{2}{*}{ ARF-GEF } & & $\begin{array}{l}\text { At5g39500 } \\
\text { (GNL1) }\end{array}$ & exchange factor \\
\hline & & $\begin{array}{l}\text { At5g19610 } \\
\text { (GNL2) }\end{array}$ & (GEF) for Arf \\
\hline
\end{tabular}

reporter revealed the highest expression levels in flowering tissues, rosettes and roots. The ZAC protein was mainly associated with membranes that were co-fractionated with Golgi and plasma membrane marker proteins. Recombinant ZAC was found to possess GTPase-activating activity on Arabidopsis Arf1A proteins, and the ZAC N-terminal region has a significant binding activity for phosphatidylinositol 3-monophosphate. These data indicate a role for ZAC in the regulation of ARF-mediated vesicular traffic. Another type of AGD protein, AGD1, is an ARF-GAP containing 
a phosphoinositide binding pleckstrin homology $(\mathrm{PH})$ domain protein. agd1 mutants have root hairs that exhibit wavy growth and have two tips that originate from a single initiation point. These root hair defects were associated with the bundling of microtubules and filamentous actin that extended to the root hair apex. Characterization of the agdl mutant provided evidence that AGD1 plays crucial roles in root hair development through the cross-talk among phosphoinositides, cytoskeleton and other signals mediated by other GTPases (Yoo et al., 2012; Yoo and Blancaflor, 2013).

A different type of AGD protein, VAN3/AGD3, contains four domains: a BAR (BIN/amphiphysin/RVS) domain, a PH domain, an ARF-GAP domain and an ankyrin (ANK)-repeat domain. VAN3 plays a pivotal role in plant venation continuity, and the recombinant protein showed GTPase-activating activity on Arf1A and a specific affinity for phosphatidylinositol. VAN3 localizes at the plasma membranes as well as in intracellular structures, including the TGN (Koizumi et al., 2005; Naramoto et al., 2009, 2010). Single-molecule fluorescence imaging showed that VAN3 localizes to discrete foci at the plasma membrane that are associated with the endocytic vesicle coat protein clathrin. Imaging studies using transgenic plants revealed that VAN3 activities are required for the endocytosis and internalization of plasma membrane proteins, including PIN-type auxin transporters. The functions and localization of other AGD proteins remain to be elucidated.

The Arabidopsis ARF-GEF protein family consists of 8 members containing the conserved Sec7 domain, and they are classified into two groups: Sec7-type and GNOM-type groups (Robinson et al., 2007) (Table 3). When compared with animal ARF-GEFs, all the Arabidopsis ARF-GEFs belong to the GBF/BIG family of animal ARF-GEFs, whereas no ARNO family exists in Arabidopsis. This is a plant-specific feature of ARFGEF divergence. Arabidopsis gnom/emb30 mutants were isolated as embryonic-lethal mutants having impairments in the first zygotic cell division and apical-basal pattern formation during early developmental processes (Shevell et al., 1994). These mutant phenotypes are very similar to the inhibition of the polarized transport of the plant hormone auxin. The GNOM/EMB30 gene encodes an ARF-GEF protein that localizes to endosomes and contributes to their structural integrity. This protein is a brefeldin A (BFA)-sensitive ARF-GEF that is required for the proper polar localization of an auxin transporter, PIN1. A molecular approach utilizing an engineered BFA-resistant version of GNOM demonstrated that GNOM is specifically required for the recycling of auxin transport components from endosomes. In contrast, the Arabidopsis GNOM-LIKE1 (GNL1) protein is a BFA-resistant ARF-GEF that localizes to the Golgi but is also required for selective internalization from the plasma membrane in the presence of BFA. This is consistent with experimental results that the internalization of an auxin efflux carrier, PIN2, was selectively inhibited in BFA-treated gnll roots. Taken together, these results suggest that both GNOM and GNL1 proteins are involved in the selective endocytosis of auxin transport components, indicating that the evolution of endocytic trafficking in plants is correlated with the neofunctionalization of GNOM-type ARF-GEFs (Geldner et al., 2003; Teh and Moore, 2007).
GNL1 and GNOM are multi-functional proteins and execute multiple roles in protein trafficking. Molecular-genetic experiments based on introduction of an engineered BFA-sensitive GNL1 into a gnl1 knockout background revealed that both a block in ER-Golgi traffic and a release of $\gamma$-COP into the cytosol were induced by addition of BFA (Richter et al., 2007). These results suggest that GNL1 is specifically required for retrograde transport from the Golgi to the ER and maintenance of Golgi integrity. GNL1 is one of the major regulators of ER-Golgi traffic but one or more BFA-sensitive ARF-GEFs are needed for its regulation because a gnl1 knockout mutant exhibits no defects in ER-Golgi traffic and Golgi integrity (Richter et al., 2007). The most recent study indicates that GNOM primarily localizes to the Golgi apparatus and that GNOM and GNL1 are colocalized at distinct subdomains on Golgi cisternae (Naramoto et al., 2014). Short-term BFA treatment stabilizes GNOM at the Golgi, whereas prolonged exposures results in GNOM translocation to the TGN/endosomes. These data are supported by the fact that GNOM can partially replace the function of GNL1 in the Golgi to ER retrograde transport, implying that GNOM might be a minor regulator of ER-Golgi traffic (Richter et al., 2007).

As for cargo specificity of endocytotic traffic, gnom and gnl1 mutants showed complicated phenotypes. In gnom mutant lines expressing BFA-resistant GNOM, a cytokinesis-specific syntaxin KNOLLE was still aggregated into large BFA bodies in the presence of BFA, suggesting that KNOLLE traffic in cytokinetic cells is dependent on other BFA-sensitive ARF-GEFs (Geldner et al., 2003). In contrast, PIN2 and PM-ATPase showed a partial BFA-resistance in the same lines, indicating that the recycling rates or transport routes of these molecules might be different between individual cells and roots (Geldner et al., 2003). In the case of gnll mutants, internalization of other molecules except PIN2 can occur normally in the absence of GNL1 function. A plasma-membrane marker PMA4-GFP and a lipophilic dye FM4-64 are accumulated in the BFA bodies of BFA-treated wild-type and gnll-2 roots with similar efficiency (Teh and Moore, 2007). These results suggest that GNL1 is not a major regulator of internalization from the plasma membrane but one or more BFA-sensitive ARF-GEFs play crucial parts in its regulation. Thus, GNL1 and GNOM execute distinct but overlapping functions in plant vesicular traffic. However, the molecular mechanisms underlying cargo specificity of the GNL1/GNOM-mediated endocytosis remain poorly elucidated. Further functional analyses coupled with molecular characterizations of other ARF-GEF proteins are necessary to elucidate fundamental aspects of ARF-GEF-mediated traffic.

Another GNOM-type ARF-GEF, GNOM-LIKE2 (GNL2), is highly expressed in pollen grains and pollen tubes. In addition, pollen germination defects were observed in the corresponding Arabidopsis mutants, gnom-like 2-1 (gnl2-1) and gnl2-2. These results suggest that GNL2-related traffic plays an important role in pollen germination (Jia et al., 2009). Thus, ARF-GEF-mediated vesicular trafficking is tightly correlated with plant developmental processes, including early embryonic development and sexual plant reproduction (Jia et al., 2009; Du et al., 2013). 


\section{CONCLUDING REMARKS}

Extensive studies by means of genetic and biochemical approaches have given rise to much progress in the understanding of the molecular mechanisms by which Sar/Arf GTPases drive vesicle formation on membrane surfaces. As discussed above, many questions remain to be answered. In particular, limited information is available on the physiological functions of Sar/Arf in plants. These GTPases achieve both housekeeping conserved functions and plant-specific functions in vesicular trafficking. To date, many unique functional differentiations have been described regarding such processes as Golgi organization, endocytic transport and cell polarity. However, further elucidation of these phenomena is required for a better understanding of multicellular development in higher plants.

\section{REFERENCES}

Anders, N., and Jurgens, G. (2008). Large ARF guanine nucleotide exchange factors in membrane trafficking. Cell. Mol. Life Sci. 65, 3433-3445. doi: 10.1007/s00018008-8227-7

Antonny, B., Beraud-Dufour, S., Chardin, P., and Chabre, M. (1997). N-terminal hydrophobic residues of the G-protein ADP-ribosylation factor-1 insert into membrane phospholipids upon GDP to GTP exchange. Biochemistry 36, 4675-4684. doi: 10.1021/bi962252b

Antonny, B., Madden, D., Hamamoto, S., Orci, L., and Schekman, R. (2001). Dynamics of the COPII coat with GTP and stable analogues. Nat. Cell Biol. 3, 531-537. doi: 10.1038/35078500

Barlowe, C., D'Enfert, C., and Schekman, R. (1993). Purification and characterization of SAR1p, a small GTP-binding protein required for transport vesicle formation from the endoplasmic reticulum. J. Biol. Chem. 268, 873-879.

Barlowe, C., Orci, L., Yeung, T., Hosobuchi, M., Hamamoto, S., Salama, N., et al. (1994). COPII: a membrane coat formed by Sec proteins that drive vesicle budding from the endoplasmic reticulum. Cell 77, 895-907. doi: 10.1016/00928674(94)90138-4

Batoko, H., Zheng, H. Q., Hawes, C., and Moore, I. (2000). A rab1 GTPase is required for transport between the endoplasmic reticulum and golgi apparatus and for normal golgi movement in plants. Plant Cell 12, 2201-2218. doi: 10.1105/tpc.12.11.2201

Beck, R., Sun, Z., Adolf, F., Rutz, C., Bassler, J., Wild, K., et al. (2008). Membrane curvature induced by Arfl-GTP is essential for vesicle formation. Proc. Natl. Acad. Sci. U.S.A. 105, 11731-11736. doi: 10.1073/pnas.0805182105

Bi, X., Corpina, R. A., and Goldberg, J. (2002). Structure of the Sec23/24-Sar1 pre-budding complex of the COPII vesicle coat. Nature 419, 271-277. doi: 10.1038/nature 01040

Bi, X., Mancias, J. D., and Goldberg, J. (2007). Insights into COPII coat nucleation from the structure of Sec23 - Sarl complexed with the active fragment of Sec31. Dev. Cell 13, 635-645. doi: 10.1016/j.devcel.2007.10.006

Bielli, A., Haney, C. J., Gabreski, G., Watkins, S. C., Bannykh, S. I., and Aridor, M. (2005). Regulation of Sar1 NH2 terminus by GTP binding and hydrolysis promotes membrane deformation to control COPII vesicle fission. J. Cell Biol. 171, 919-924. doi: 10.1083/jcb.200509095

Bigay, J., Casella, J. F., Drin, G., Mesmin, B., and Antonny, B. (2005). ArfGAP1 responds to membrane curvature through the folding of a lipid packing sensor motif. EMBO J. 24, 2244-2253. doi: 10.1038/sj.emboj.7600714

Bohlenius, H., Morch, S. M., Godfrey, D., Nielsen, M. E., and ThordalChristensen, H. (2010). The multivesicular body-localized GTPase ARFAlb/lc is important for callose deposition and ROR2 syntaxin-dependent preinvasive basal defense in barley. Plant Cell 22, 3831-3844. doi: 10.1105/tpc.55-56110. 078063

Brandizzi, F., and Barlowe, C. (2013). Organization of the ER-Golgi interface for membrane traffic control. Nat. Rev. Mol. Cell Biol. 14, 382-392. doi: $10.1038 / \mathrm{nrm} 3588$

Cai, H., Yu, S., Menon, S., Cai, Y., Lazarova, D., Fu, C., et al. (2007). TRAPPI tethers COPII vesicles by binding the coat subunit Sec23. Nature 445, 941-944. doi: 10.1038/nature05527

Chantalat, S., Courbeyrette, R., Senic-Matuglia, F., Jackson, C. L., Goud, B., and Peyroche, A. (2003). A novel golgi membrane protein is a partner of the
ARF exchange factors Gea1p and Gea2p. Mol. Biol. Cell 14, 2357-2371. doi: 10.1091/mbc.E02-10-0693

Connerly, P. L., Esaki, M., Montegna, E. A., Strongin, D. E., Levi, S., Soderholm, J., et al. (2005). Sec16 is a determinant of transitional ER organization. Curr. Biol. 15, 1439-1447. doi: 10.1016/j.cub.2005.06.065

Dasilva, L. L., Snapp, E. L., Denecke, J., Lippincott-Schwartz, J., Hawes, C., and Brandizzi, F. (2004). Endoplasmic reticulum export sites and golgi bodies behave as single mobile secretory units in plant cells. Plant Cell 16, 1753-1771. doi: $10.1105 /$ tpc. 022673

De Craene, J. O., Courte, F., Rinaldi, B., Fitterer, C., Herranz, M. C., SchmittKeichinger, C., et al. (2014). Study of the plant COPII vesicle coat subunits by functional complementation of yeast Saccharomyces cerevisiae mutants. PLoS ONE 9:e90072. doi: 10.1371/journal.pone.0090072

D'Enfert, C., Gensse, M., and Gaillardin, C. (1992). Fission yeast and a plant have functional homologues of the Sar1 and Sec12 proteins involved in ER to golgi traffic in budding yeast. EMBO J. 11, 4205-4211.

Du, W., Tamura, K., Stefano, G., and Brandizzi, F. (2013). The integrity of the plant golgi apparatus depends on cell growth-controlled activity of GNL1. Mol. Plant 6, 905-915. doi: 10.1093/mp/sss124

Espenshade, P., Gimeno, R. E., Holzmacher, E., Teung, P., and Kaiser, C. A. (1995). Yeast SEC16 gene encodes a multidomain vesicle coat protein that interacts with Sec23p. J. Cell Biol. 131, 311-324. doi: 10.1083/jcb.131.2.311

Faso, C., Chen, Y. N., Tamura, K., Held, M., Zemelis, S., Marti, L., et al. (2009). A missense mutation in the Arabidopsis COPII coat protein Sec24A induces the formation of clusters of the endoplasmic reticulum and golgi apparatus. Plant Cell 21, 3655-3671. doi: 10.1105/tpc.109.068262

Fatal, N., Karhinen, L., Jokitalo, E., and Makarow, M. (2004). Active and specific recruitment of a soluble cargo protein for endoplasmic reticulum exit in the absence of functional COPII component Sec24p. J. Cell Sci. 117, 1665-1673. doi: $10.1242 /$ jcs. 01019

Franco, M., Chardin, P., Chabre, M., and Paris, S. (1996). Myristoylation-facilitated binding of the G protein ARF1GDP to membrane phospholipids is required for its activation by a soluble nucleotide exchange factor. J. Biol. Chem. 271, 1573-1578. doi: 10.1074/jbc.271.3.1573

Futai, F., Hamamoto, S., Orci, L., and Schekman, R. (2004). GTP/GDP exchange by Sec12p enables COPII vesicle bud formation on synthetic liposomes. EMBO J. 23, 4146-4155. doi: 10.1038/sj.emboj.7600428

Geldner, N., Anders, N., Wolters, H., Keicher, J., Kornberger, W., Muller, P., et al. (2003). The Arabidopsis GNOM ARF-GEF mediates endosomal recycling, auxin transport, and auxin-dependent plant growth. Cell 112, 219-230. doi: $10.1016 / 50092-8674(03) 00003-5$

Goldberg, J. (1998). Structural basis for activation of ARF GTPase: mechanisms of guanine nucleotide exchange and GTP-myristoyl switching. Cell 95, 237-248. doi: 10.1016/S0092-8674(00)81754-7

Gonzalez, E., Solano, R., Rubio, V., Leyva, A., and Paz-Ares, J. (2005). PHOSPHATE TRANSPORTER TRAFFIC FACILITATOR1 is a plant-specific SEC12-related protein that enables the endoplasmic reticulum exit of a highaffinity phosphate transporter in Arabidopsis. Plant Cell 17, 3500-3512. doi: $10.1105 /$ tpc. 105.036640

Hanton, S. L., Chatre, L., Matheson, L. A., Rossi, M., Held, M. A., and Brandizzi, F. (2008). Plant Sarl isoforms with near-identical protein sequences exhibit different localisations and effects on secretion. Plant Mol. Biol. 67, 283-294. doi: 10.1007/s11103-008-9317-5

Hara-Kuge, S., Kuge, O., Orci, L., Amherdt, M., Ravazzola, M., Wieland, F. T., et al. (1994). En bloc incorporation of coatomer subunits during the assembly of COP-coated vesicles. J. Cell Biol. 124, 883-892. doi: 10.1083/jcb.124.6.883

Jensen, R. B., Lykke-Andersen, K., Frandsen, G. I., Nielsen, H. B., Haseloff, J., Jespersen, H. M., et al. (2000). Promiscuous and specific phospholipid binding by domains in ZAC, a membrane-associated Arabidopsis protein with an ARF GAP zinc finger and a C2 domain. Plant Mol. Biol. 44, 799-814. doi: 10.1023/A:1026509002161

Jia, D. J., Cao, X., Wang, W., Tan, X. Y., Zhang, X. Q., Chen, L. Q., et al. (2009). GNOM-LIKE 2, encoding an adenosine diphosphate-ribosylation factor-guanine nucleotide exchange factor protein homologous to GNOM and GNL1, is essential for pollen germination in Arabidopsis. J. Integr. Plant Biol. 51, 762-773. doi: 10.1111/j.1744-7909.2009.00858.x

Jurgens, G., and Geldner, N. (2002). Protein secretion in plants: from the transGolgi network to the outer space. Traffic 3, 605-613. doi: 10.1034/j.16000854.2002.30902.x 
Kahn, R. A., Clark, J., Rulka, C., Stearns, T., Zhang, C. J., Randazzo, P. A., et al. (1995). Mutational analysis of Saccharomyces cerevisiae ARF1. J. Biol. Chem. 270, 143-150. doi: 10.1074/jbc.270.1.143

Kahn, R. A., Goddard, C., and Newkirk, M. (1988). Chemical and immunological characterization of the 21-kDa ADP-ribosylation factor of adenylate cyclase. J. Biol. Chem. 263, 8282-8287.

Kim, W. Y., Cheong, N. E., Je, D. Y., Kim, M. G., Lim, C. O., Bahk, J. D., et al. (1997). The presence of a Sarl gene family in Brassica campestris that suppresses a yeast vesicular transport mutation Sec12-1. Plant Mol. Biol. 33, 1025-1035. doi: 10.1023/A:1005731209124

Kodera, C., Yorimitsu, T., Nakano, A., and Sato, K. (2011). Sed4p stimulates Sarlp GTP hydrolysis and promotes limited coat disassembly. Traffic 12, 591-599. doi: 10.1111/j.1600-0854.2011.01173.x

Koizumi, K., Naramoto, S., Sawa, S., Yahara, N., Ueda, T., Nakano, A., et al. (2005). VAN3 ARF-GAP-mediated vesicle transport is involved in leaf vascular network formation. Development 132, 1699-1711. doi: 10.1242/dev.01716

Krauss, M., Jia, J. Y., Roux, A., Beck, R., Wieland, F. T., De Camilli, P., et al. (2008). Arf1-GTP-induced tubule formation suggests a function of Arf family proteins in curvature acquisition at sites of vesicle budding. J. Biol. Chem. 283, 27717-27723. doi: 10.1074/jbc.M804528200

Kung, L. F., Pagant, S., Futai, E., D’Arcangelo, J. G., Buchanan, R., Dittmar, J. C., et al. (2012). Sec24p and Sec16p cooperate to regulate the GTP cycle of the COPII coat. EMBO J. 31, 1014-1027. doi: 10.1038/emboj.2011.444

Kurokawa, K., Okamoto, M., and Nakano, A. (2014). Contact of cis-Golgi with ER exit sites executes cargo capture and delivery from the ER. Nat. Commun. 5, 3653. doi: 10.1038/ncomms4653

Langhans, M., Meckel, T., Kress, A., Lerich, A., and Robinson, D. G. (2012). ERES (ER exit sites) and the "secretory unit concept." J. Microsc. 247, 48-59. doi: 10.1111/j.1365-2818.2011.03597.x

Lee, C., and Goldberg, J. (2010). Structure of coatomer cage proteins and the relationship among COPI, COPII, and clathrin vesicle coats. Cell 142, 123-132. doi: 10.1016/j.cell.2010.05.030

Lee, M. C., Orci, L., Hamamoto, S., Futai, E., Ravazzola, M., and Schekman, R. (2005). Sarlp N-terminal helix initiates membrane curvature and completes the fission of a COPII vesicle. Cell 122, 605-617. doi: 10.1016/j.cell.2005.07.025

Lee, M. H., Min, M. K., Lee, Y. J., Jin, J. B., Shin, D. H., Kim, D. H., et al. (2002). ADP-ribosylation factor 1 of Arabidopsis plays a critical role in intracellular trafficking and maintenance of endoplasmic reticulum morphology in Arabidopsis. Plant Physiol. 129, 1507-1520. doi: 10.1104/pp.003624

Lerich, A., Hillmer, S., Langhans, M., Scheuring, D., Van Bentum, P., and Robinson, D. G. (2012). ER import sites and their relationship to ER exit sites: a new model for bidirectional ER-Golgi transport in higher plants. Front. Plant Sci. 3:143. doi: 10.3389/fpls.2012.00143

Letourneur, F., Gaynor, E. C., Hennecke, S., Demolliere, C., Duden, R., Emr, S. D., et al. (1994). Coatomer is essential for retrieval of dilysine-tagged proteins to the endoplasmic reticulum. Cell 79, 1199-1207. doi: 10.1016/00928674(94)90011-6

Lord, C., Bhandari, D., Menon, S., Ghassemian, M., Nycz, D., Hay, J., et al. (2011). Sequential interactions with Sec 23 control the direction of vesicle traffic. Nature 473, 181-186. doi: 10.1038/nature09969

Lundmark, R., Doherty, G. J., Vallis, Y., Peter, B. J., and McMahon, H. T. (2008). Arf family GTP loading is activated by, and generates, positive membrane curvature. Biochem. J. 414, 189-194. doi: 10.1042/BJ20081237

Macia, E., Chabre, M., and Franco, M. (2001). Specificities for the small G proteins ARF1 and ARF6 of the guanine nucleotide exchange factors ARNO and EFA6. J. Biol. Chem. 276, 24925-24930. doi: 10.1074/jbc.M103284200

Marti, L., Fornaciari, S., Renna, L., Stefano, G., and Brandizzi, F. (2010). COPII-mediated traffic in plants. Trends Plant Sci. 15, 522-528. doi: 10.1016/j.tplants.2010.05.010

Matheson, L. A., Suri, S. S., Hanton, S. L., Chatre, L., and Brandizzi, F. (2008). Correct targeting of plant ARF GTPases relies on distinct protein domains. Traffic 9, 103-120. doi: 10.1111/j.1600-0854.2007.00671.x

Matsuoka, K., Orci, L., Amherdt, M., Bednarek, S. Y., Hamamoto, S., Schekman, R., et al. (1998). COPII-coated vesicle formation reconstituted with purified coat proteins and chemically defined liposomes. Cell 93, 263-275. doi: 10.1016/S0092-8674(00)81577-9

McMahon, C., Studer, S. M., Clendinen, C., Dann, G. P., Jeffrey, P. D., and Hughson, F. M. (2012). The structure of Sec12 implicates potassium ion coordination in Sar1 activation. J. Biol. Chem. 287, 43599-43606. doi: 10.1074/jbc.M112.420141
Miller, E. A., Beilharz, T. H., Malkus, P. N., Lee, M. C., Hamamoto, S., Orci, L., et al. (2003). Multiple cargo binding sites on the COPII subunit Sec24p ensure capture of diverse membrane proteins into transport vesicles. Cell 114, 497-509. doi: 10.1016/S0092-8674(03)00609-3

Min, M. K., Jang, M., Lee, M., Lee, J., Song, K., Lee, Y., et al. (2013). Recruitment of Arfl-GDP to Golgi by Glo3p-type ArfGAPs is crucial for golgi maintenance and plant growth. Plant Physiol. 161, 676-691. doi: 10.1104/pp.112.209148

Min, M. K., Kim, S. J., Miao, Y., Shin, J., Jiang, L., and Hwang, I. (2007). Overexpression of Arabidopsis AGD7 causes relocation of Golgi-localized proteins to the endoplasmic reticulum and inhibits protein trafficking in plant cells. Plant Physiol. 143, 1601-1614. doi: 10.1104/pp.106.095091

Mironov, A. A. (2014). ER-Golgi transport could occur in the absence of COPII vesicles. Nat. Rev. Mol. Cell Biol. 15, 1. doi: 10.1038/nrm3588-c1

Mossessova, E., Bickford, L. C., and Goldberg, J. (2003). SNARE selectivity of the COPII coat. Cell 114, 483-495. doi: 10.1016/S0092-8674(03)00608-1

Nakano, A., Brada, D., and Schekman, R. (1988). A membrane glycoprotein, Sec12p, required for protein transport from the endoplasmic reticulum to the Golgi apparatus in yeast. J. Cell Biol. 107, 851-863. doi: 10.1083/jcb. 107.3.851

Nakano, R. T., Matsushima, R., Ueda, H., Tamura, K., Shimada, T., Li, L., et al. (2009). GNOM-LIKE1/ERMO1 and SEC24a/ERMO2 are required for maintenance of endoplasmic reticulum morphology in Arabidopsis thaliana. Plant Cell 21, 3672-3685. doi: 10.1105/tpc.109.068270

Naramoto, S., Kleine-Vehn, J., Robert, S., Fujimoto, M., Dainobu, T., Paciorek, T., et al. (2010). ADP-ribosylation factor machinery mediates endocytosis in plant cells. Proc. Natl. Acad. Sci. U.S.A. 107, 21890-21895. doi: $10.1073 /$ pnas. 1016260107

Naramoto, S., Otegui, M. S., Kutsuna, N., De Rycke, R., Dainobu, T., Karampelias, M., et al. (2014). Insights into the localization and function of the membrane trafficking regulator GNOM ARF-GEF at the Golgi apparatus in Arabidopsis. Plant Cell. doi: 10.1105/tpc.114.125880. [Epub ahead of print].

Naramoto, S., Sawa, S., Koizumi, K., Uemura, T., Ueda, T., Friml, J., et al. (2009). Phosphoinositide-dependent regulation of VAN3 ARF-GAP localization and activity essential for vascular tissue continuity in plants. Development 136, 1529-1538. doi: 10.1242/dev.030098

Novick, P., Field, C., and Schekman, R. (1980). Identification of 23 complementation groups required for post-translational events in the yeast secretory pathway. Cell 21, 205-215. doi: 10.1016/0092-8674(80)90128-2

Osterrieder, A., Hummel, E., Carvalho, C. M., and Hawes, C. (2010). Golgi membrane dynamics after induction of a dominant-negative mutant Sarl GTPase in tobacco. J. Exp. Bot. 61, 405-422. doi: 10.1093/jxb/erp315

Paciorek, T., Zazimalova, E., Ruthardt, N., Petrasek, J., Stierhof, Y. D., Kleine-Vehn, J., et al. (2005). Auxin inhibits endocytosis and promotes its own efflux from cells. Nature 435, 1251-1256. doi: 10.1038/nature03633

Peyroche, A., Courbeyrette, R., Rambourg, A., and Jackson, C. L. (2001). The ARF exchange factors Gealp and Gea2p regulate Golgi structure and function in yeast. J. Cell Sci. 114, 2241-2253.

Peyroche, A., Paris, S., and Jackson, C. L. (1996). Nucleotide exchange on ARF mediated by yeast Geal protein. Nature 384, 479-481. doi: 10.1038/ $384479 \mathrm{a} 0$

Phillipson, B. A., Pimpl, P., Dasilva, L. L., Crofts, A. J., Taylor, J. P., Movafeghi, A., et al. (2001). Secretory bulk flow of soluble proteins is efficient and COPII dependent. Plant Cell 13, 2005-2020. doi: 10.1105/tpc.13.9.2005

Pimpl, P., Hanton, S. L., Taylor, J. P., Pinto-Dasilva, L. L., and Denecke, J. (2003). The GTPase ARF1p controls the sequence-specific vacuolar sorting route to the lytic vacuole. Plant Cell 15, 1242-1256. doi: 10.1105/tpc.010140

Pimpl, P., Movafeghi, A., Coughlan, S., Denecke, J., Hillmer, S., and Robinson, D. G. (2000). In situ localization and in vitro induction of plant COPI-coated vesicles. Plant Cell 12, 2219-2236. doi: 10.1105/tpc.12.11.2219

Poon, P. P., Cassel, D., Spang, A., Rotman, M., Pick, E., Singer, R. A., et al. (1999). Retrograde transport from the yeast Golgi is mediated by two ARF GAP proteins with overlapping function. EMBO J. 18, 555-564. doi: 10.1093/emboj/ 18.3.555

Richter, S., Geldner, N., Schrader, J., Wolters, H., Stierhof, Y. D., Rios, G., et al. (2007). Functional diversification of closely related ARF-GEFs in protein secretion and recycling. Nature 448, 488-492. doi: 10.1038/nature05967

Robinson, D. G., Herranz, M. C., Bubeck, J., Pepperkok, R., and Ritzenthaler, C. (2007). Membrane dynamics in the early secretory pathway. Crit. Rev. Plant Sci. 26, 199-225. doi: 10.1080/07352680701495820 
Robinson, D. G., Scheuring, D., Naramoto, S., and Friml, J. (2011). ARF1 localizes to the golgi and the trans-golgi network. Plant Cell 23, 846-849, 849-850. doi: 10.1105/tpc. 110.082099

Saito, Y., Kimura, K., Oka, T., and Nakano, A. (1998). Activities of mutant Sar1 proteins in guanine nucleotide binding, GTP hydrolysis, and cell-free transport from the endoplasmic reticulum to the Golgi apparatus. J. Biochem. 124, 816-823. doi: 10.1093/oxfordjournals.jbchem.a022185

Sato, M., Sato, K., and Nakano, A. (1996). Endoplasmic reticulum localization of Sec12p is achieved by two mechanisms: Rerlp-dependent retrieval that requires the transmembrane domain and Rerlp-independent retention that involves the cytoplasmic domain. J. Cell Biol. 134, 279-293. doi: 10.1083/jcb.134.2.279

Sewell, J. L., and Kahn, R. A. (1988). Sequences of the bovine and yeast ADPribosylation factor and comparison to other GTP-binding proteins. Proc. Natl. Acad. Sci. U.S.A. 85, 4620-4624. doi: 10.1073/pnas.85.13.4620

Shaywitz, D. A., Espenshade, P. J., Gimeno, R. E., and Kaiser, C. A. (1997). COPII Subunit interactions in the assembly of the vesicle coat. J. Biol. Chem. 272, 25413-25416. doi: 10.1074/jbc.272.41.25413

Shevell, D. E., Leu, W. M., Gillmor, C. S., Xia, G., Feldmann, K. A., and Chua, N. H. (1994). EMB30 is essential for normal cell division, cell expansion, and cell adhesion in Arabidopsis and encodes a protein that has similarity to Sec7. Cell 77, 1051-1062. doi: 10.1016/0092-8674(94)90444-8

Shiba, Y., and Randazzo, P. A. (2012). ArfGAP1 function in COPI mediated membrane traffic: currently debated models and comparison to other coat-binding ArfGAPs. Histol. Histopathol. 27, 1143-1153.

Spang, A., Matsuoka, K., Hamamoto, S., Schekman, R., and Orci, L. (1998). Coatomer, Arflp, and nucleotide are required to bud coat protein complex Icoated vesicles from large synthetic liposomes. Proc. Natl. Acad. Sci. U.S.A. 95, 11199-11204. doi: 10.1073/pnas.95.19.11199

Spang, A., Shiba, Y., and Randazzo, P. A. (2010). Arf GAPs: gatekeepers of vesicle generation. FEBS Lett. 584, 2646-2651. doi: 10.1016/j.febslet.2010.04.005

Stachowiak, J. C., Schmid, E. M., Ryan, C. J., Ann, H. S., Sasaki, D. Y., Sherman, M. B., et al. (2012). Membrane bending by protein-protein crowding. Nat. Cell Biol. 14, 944-949. doi: 10.1038/ncb2561

Stagg, S. M., Gurkan, C., Fowler, D. M., Lapointe, P., Foss, T. R., Potter, C. S., et al. (2006). Structure of the Sec13/31 COPII coat cage. Nature 439, 234-238. doi: 10.1038 /nature04339

Stefano, G., Renna, L., Chatre, L., Hanton, S. L., Moreau, P., Hawes, C., et al. (2006). In tobacco leaf epidermal cells, the integrity of protein export from the endoplasmic reticulum and of ER export sites depends on active COPI machinery. Plant J. 46, 95-110. doi: 10.1111/j.1365-313X.2006.02675.x

Stefano, G., Renna, L., Rossi, M., Azzarello, E., Pollastri, S., Brandizzi, F., et al. (2010). AGD5 is a GTPase-activating protein at the trans-Golgi network. Plant J. 64, 790-799. doi: 10.1111/j.1365-313X.2010.04369.x

Stierhof, Y. D., and El Kasmi, F. (2010). Strategies to improve the antigenicity, ultrastructure preservation and visibility of trafficking compartments in Arabidopsis tissue. Eur. J. Cell Biol. 89, 285-297. doi: 10.1016/j.ejcb.2009.12.003

Supek, F., Madden, D. T., Hamamoto, S., Orci, L., and Schekman, R. (2002). Sec16p potentiates the action of COPII proteins to bud transport vesicles. J. Cell Biol. 158, 1029-1038. doi: 10.1083/jcb.200207053

Tabata, K. V., Sato, K., Ide, T., Nishizaka, T., Nakano, A., and Noji, H. (2009). Visualization of cargo concentration by COPII minimal machinery in a planar lipid membrane. EMBO J. 28, 3279-3289. doi: 10.1038/emboj.2009.269

Takeuchi, M., Tada, M., Saito, C., Yashiroda, H., and Nakano, A. (1998). Isolation of a tobacco cDNA encoding Sar1 GTPase and analysis of its dominant mutations in vesicular traffic using a yeast complementation system. Plant Cell Physiol. 39, 590-599. doi: 10.1093/oxfordjournals.pcp.a029409

Takeuchi, M., Ueda, T., Sato, K., Abe, H., Nagata, T., and Nakano, A. (2000). A dominant negative mutant of sarl GTPase inhibits protein transport from the endoplasmic reticulum to the Golgi apparatus in tobacco and Arabidopsis cultured cells. Plant J. 23, 517-525. doi: 10.1046/j.1365-313x.2000.00823.x

Takeuchi, M., Ueda, T., Yahara, N., and Nakano, A. (2002). Arf1 GTPase plays roles in the protein traffic between the endoplasmic reticulum and the Golgi apparatus in tobacco and Arabidopsis cultured cells. Plant J. 31, 499-515. doi: 10.1046/j.1365-313X.2002.01372.x

Tanabe, K., Torii, T., Natsume, W., Braesch-Andersen, S., Watanabe, T., and Satake, M. (2005). A novel GTPase-activating protein for ARF6 directly interacts with clathrin and regulates clathrin-dependent endocytosis. Mol. Biol. Cell 16, 1617-1628. doi: 10.1091/mbc.E04-08-0683

Tanaka, H., Kitakura, S., De Rycke, R., De Groodt, R., and Friml, J. (2009). Fluorescence imaging-based screen identifies ARF GEF component of early endosomal trafficking. Curr. Biol. 19, 391-397. doi: 10.1016/j.cub.2009.01.057

Tanaka, Y., Nishimura, K., Kawamukai, M., Oshima, A., and Nakagawa, T. (2013). Redundant function of two Arabidopsis COPII components, AtSec24B and AtSec24C, is essential for male and female gametogenesis. Planta 238, 561-575. doi: 10.1007/s00425-013-1913-1

Teh, O. K., and Moore, I. (2007). An ARF-GEF acting at the Golgi and in selective endocytosis in polarized plant cells. Nature 448, 493-496. doi: 10.1038/nature06023

Tian, L., Dai, L. L., Yin, Z. J., Fukuda, M., Kumamaru, T., Dong, X. B., et al. (2013). Small GTPase Sarl is crucial for proglutelin and alpha-globulin export from the endoplasmic reticulum in rice endosperm. J. Exp. Bot. 64, 2831-2845. doi: 10.1093/jxb/ert128

Vernoud, V., Horton, A. C., Yang, Z., and Nielsen, E. (2003). Analysis of the small GTPase gene superfamily of Arabidopsis. Plant Physiol. 131, 1191-1208. doi: 10.1104/pp.013052

Xu, J., and Scheres, B. (2005). Dissection of Arabidopsis ADP-RIBOSYLATION FACTOR 1 function in epidermal cell polarity. Plant Cell 17, 525-536. doi: 10.1105/tpc.104.028449

Yahara, N., Ueda, T., Sato, K., and Nakano, A. (2001). Multiple roles of Arf1 GTPase in the yeast exocytic and endocytic pathways. Mol. Biol. Cell 12, 221-238. doi: 10.1091/mbc.12.1.221

Yang, Y. D., Elamawi, R., Bubeck, J., Pepperkok, R., Ritzenthaler, C., and Robinson, D. G. (2005). Dynamics of COPII vesicles and the Golgi apparatus in cultured Nicotiana tabacum BY-2 cells provides evidence for transient association of Golgi stacks with endoplasmic reticulum exit sites. Plant Cell 17, 1513-1531. doi: $10.1105 /$ tpc. 104.026757

Yoo, C. M., and Blancaflor, E. B. (2013). Overlapping and divergent signaling pathways for ARK1 and AGD1 in the control of root hair polarity in Arabidopsis thaliana. Front. Plant Sci. 4:528. doi: 10.3389/fpls.2013.00528

Yoo, C. M., Quan, L., Cannon, A. E., Wen, J., and Blancaflor, E. B. (2012). AGD1, a class 1 ARF-GAP, acts in common signaling pathways with phosphoinositide metabolism and the actin cytoskeleton in controlling Arabidopsis root hair polarity. Plant J. 69, 1064-1076. doi: 10.1111/j.1365-313X.2011.04856.x

Yorimitsu, T., and Sato, K. (2012). Insights into structural and regulatory roles of Sec16 in COPII vesicle formation at ER exit sites. Mol. Biol. Cell 23, 2930-2942. doi: 10.1091/mbc.E12-05-0356

Yoshihisa, T., Barlowe, C., and Schekman, R. (1993). Requirement for a GTPaseactivating protein in vesicle budding from the endoplasmic reticulum. Science 259, 1466-1468. doi: 10.1126/science.8451644

Yu, X., Breitman, M., and Goldberg, J. (2012). A structure-based mechanism for Arf1-dependent recruitment of coatomer to membranes. Cell 148, 530-542. doi: 10.1016/j.cell.2012.01.015

Zhang, C. J., Cavenagh, M. M., and Kahn, R. A. (1998). A family of Arf effectors defined as suppressors of the loss of Arf function in the yeast Saccharomyces cerevisiae. J. Biol. Chem. 273, 19792-19796. doi: 10.1074/jbc.273.31.19792

Conflict of Interest Statement: The authors declare that the research was conducted in the absence of any commercial or financial relationships that could be construed as a potential conflict of interest.

Received: 27 June 2014; accepted: 03 August 2014; published online: 21 August 2014. Citation: Yorimitsu T, Sato K and Takeuchi M (2014) Molecular mechanisms of Sar/Arf GTPases in vesicular trafficking in yeast and plants. Front. Plant Sci. 5:411. doi: $10.3389 / \mathrm{fpls} .2014 .00411$

This article was submitted to Plant Traffic and Transport, a section of the journal Frontiers in Plant Science.

Copyright (c) 2014 Yorimitsu, Sato and Takeuchi. This is an open-access article distributed under the terms of the Creative Commons Attribution License (CC BY). The use, distribution or reproduction in other forums is permitted, provided the original author(s) or licensor are credited and that the original publication in this journal is cited, in accordance with accepted academic practice. No use, distribution or reproduction is permitted which does not comply with these terms. 